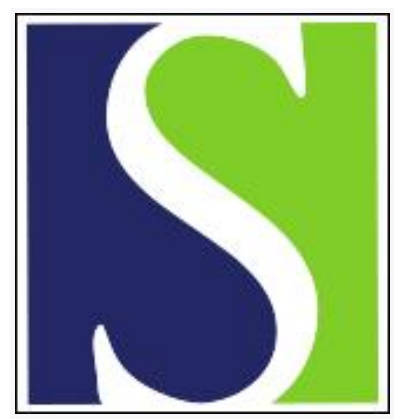

Scand J Work Environ Health 2018;44(1):108-110

https://doi.org/10.5271/sjweh.3698

Published online: 08 Dec 2017, Issue date: 01 Jan 2018

Response to letter to the editor from Dr Rahman Shiri: The challenging topic of suicide across occupational groups

by Niedhammer I, Milner A, Witt K, Klingelschmidt J, Khireddine-Medouni I, Alexopoulos EC, Toivanen S, Chastang J-F, LaMontagne AD

Affiliation: INSERM, U1085, Research Institute for Environmental and Occupational Health (IRSET), Epidemiology in Occupational Health and Ergonomics (ESTER) Team, Angers, France. isabelle.niedhammer@inserm.fr

Refers to the following texts of the Journal: 2018;44(1):106-107 2018;44(1):3-15

Key terms: agriculture; farmer; fishery worker; forestry worker; letter; occupational group; response; suicide

This article in PubMed: www.ncbi.nlm.nih.gov/pubmed/29218357 


\section{Response to letter to the editor from Dr Rahman Shiri: The challenging topic of suicide across occupational groups}

We thank Dr Rahman Shiri (1) for his careful reading of our systematic review and meta-analysis on suicide among agricultural, forestry, and fishery workers (2). Our paper had the objective of providing a pooled effect size of suicide for this occupational group.

Suicide is a crucial issue in public and occupational health. Suicide has a multifactorial etiology and recent systematic reviews and meta-analyses have pointed out the role of occupational exposures, mainly psychosocial work stressors, as risk factors for suicide $(3,4)$. Suicide is a very rare event in the general population and still more seldom in the working population. Indeed, unemployed and economically inactive people have a higher risk of suicide compared to employed people (5, 6 ). However, the total number of suicides is greater in the employed population than among the economically inactive or unemployed (6).

Shiri's letter (1) questioned several aspects of our review and meta-analysis. One comment related to the single reference database used in our review and a suggestion that our review could not be considered to be systematic. The review was based on Medline because our main interest was in quantitative epidemiologic studies. This is the largest database for biomedical literature and we would argue the most pertinent. Furthermore, we checked the reference lists of the most recent papers and literature reviews, and Shiri did not report any paper that was missing. No review, whether searching one or more databases, can expect to be totally exhaustive. There may always be missing studies, especially if we consider grey literature. Thus we assert that our review was systematic, while acknowledging that it may not be perfectly comprehensive.

Shiri suggested an absence of quality assessment of the studies included in our meta-analysis. First, quality was considered in the context of our comments in the discussion section. Second, as suggested by Rothman et al (7), quality assessment was replaced by regression analyses of the effect of each quality item (study characteristics, ie, study design, effect measure, reference group, and adjustment). Third, because most studies included in this review were based on objective data (census, administrative, or register data), they were free of many of the sources of bias that exist in studies where information on exposure and outcome must be collected from participants. Consequently, many of the items related to quality were not pertinent, such as response and follow-up rates, coverage and representativeness of the sample, selection, etc. Contrary to what Shiri suggested, all study designs can be informative in this topic because all of them are able to provide an unbiased estimate of the effect size. In addition, the prospective and case-control studies may have shortcomings. For example, we excluded five studies including three prospective and case-control studies in the sensibility analysis because the group of interest was defined on the basis of the exposure to chemicals (pesticides) rather than job title.

Our choice to retain the least adjusted models was justified because aggregated data were used for the meta-analysis. Therefore, unless all included studies adjusted for the same covariates measured in the same way, adjusted estimates cannot be meaningfully provided in an aggregate data meta-analysis. In addition, as the objective was above all descriptive and not etiological or explanatory, and as it is the norm in the exploration of social inequalities in health (8), the results from the least (gender- and age-) adjusted models were in line with the objective. Indeed, including more adjustment variables could lead to overadjustment as they may be intermediate variables on the causal pathways between occupation and suicide. Our strategy was in line with previous meta-analyses on similar topics $(9-11)$. Consequently, we would argue that our results are not likely to be largely due to confounding, contrary to the comment by Shiri. Indeed, the study of the contribution of underlying factors in explaining social inequalities in health outcomes is a fully-fledged topic of research (12-15), but this is relevant research to conduct after demonstrating that inequalities exist between social or occupational groups.

Several of Shiri's comments were about statistical aspects of our analyses. First, it was suggested that we did not correctly extract the confidence intervals for the estimates of several studies. We disagree. We used the STATA metan suite of commands using log-transformed effect sizes and standard errors. Our figure 1 and the values of effect sizes and confidence intervals were provided by STATA, this explains why there may be small differences in these values compared with the results published in some studies. Using log-transformed effect sizes and confidence intervals, the analysis provided the 
same results. Second, our subgroup comparison was based on subsamples that were independent. As not all studies provided information for these subgroups, each subgroup was treated as a unit of analysis. This strategy allows the use of all relevant subgroups and comparisons between them (16). Third, we were also criticized for the use of random-effects models. Random-effects models are generally more plausible for meta-analysis based on studies from the published literature, because the fixedeffect model assumed that the entire corpus of literature has been obtained, ie, that every study has been or ever will be written on the topic has been included, which is an implausible assumption. We also assumed differences in effect size between studies and between subgroups, and the use of random-effects models was consistent with such an assumption. However, random-effects models produce wider confidence intervals compared to fixed-effect models (16). These models are thus more conservative, making our results all the more robust.

One of Shiri's comments related to the reference group used in the studies for the comparison of agricultural, forestry, and fishery workers. Although we reported that the studies using a specific occupational group as reference group provided a higher effect size than the studies using other reference groups, we did not explicitly recognize and state in the paper that the results for Japan were based on two studies using a specific occupational group as reference; we concede that this may explain why we found a much more elevated effect size for Japan. Shiri's results (1) allow to conclude that the difference between Japan and the other geographic areas could be explained by the choice of reference group - we are grateful to him for raising this point. However, we would note that the effect size of suicide was still elevated and significant for agricultural, forestry, and fishery workers even after this change in the reference group for these two studies.

Nevertheless, the choice of the optimal reference group is not obvious. If we consider the general population as the reference group, as unemployed people and economically inactive people (including people who may not be working due to illness or disability) are part of it and have a higher risk of suicide than employed people, the effect size provided by the nine studies using the general population as the reference is likely to be underestimated, which may contribute to an underestimation of the observed effect size of suicide among agricultural, forestry, and fishery workers in our study. The comparison was made in our paper with the other occupational groups (ie, the working population except the group of interest) as the reference, which was used by nine other studies, but this did not allow to determine the exact rank of the group of interest in the occupational hierarchy. Another relevant choice would have been to retain the group with the lowest suicide risk (for example, the high-skilled occupational group) as the reference, which would have led to a much higher effect size of suicide for agricultural, forestry, and fishery workers.

To conclude, as statistical power in detecting differences between subgroups may be low in subgroup analyses and meta-regression, the absence of significant results according to subgroups found in our results cannot be interpreted as evidence that the effect size is the same across subgroups. Consequently, our meta-analysis reporting a significant excess of risk of suicide among agricultural, forestry, and fishery workers may also be a good incentive for more research among this group of workers to (i) confirm this observed excess of risk using differing methodological approaches to meta-analysis and (ii) explore the potential differences within this group and the underlying factors that may explain this excess of risk.

\section{References}

1. Shiri R. Suicide among agricultural, forestry, and fishery workers. Scand J Work Environ Health. 2018;44(1):106-107. https://doi.org/10.5271/sjweh.3697

2. Klingelschmidt J, Milner A, Khireddine-Medouni I, Witt $\mathrm{K}$, Alexopoulos EC, Toivanen S, et al. Suicide among agricultural, forestry, and fishery workers: a systematic literature review and meta-analysis. Scand J Work Environ Health. 2018;44(1):3-15. https://doi.org/10.5271/sjweh.3682

3. Milner A, Witt K, LaMontagne AD, Niedhammer I. Psychosocial job stressors and suicidality: a meta-analysis and systematic review. Occup Environ Med - online first. https:// doi.org/10.1136/oemed-2017-104531

4. Leach LS, Poyser C, Butterworth P. Workplace bullying and the association with suicidal ideation/thoughts and behaviour: a systematic review. Occup Environ Med. 2017;74(1):72-9. https://doi.org/10.1136/oemed-2016-103726

5. Milner A, Page A, LaMontagne AD. Long-term unemployment and suicide: a systematic review and meta-analysis. PLoS One. 2013;8(1):e51333. https://doi.org/10.1371/journal. pone. 0051333

6. Milner A, Morrell S, Lamontagne AD. Economically inactive, unemployed and employed suicides in Australia by age and sex over a 10-year period: what was the impact of the 2007 economic recession? Int J Epidemiol. 2014;43(5):1500-7. https://doi.org/10.1093/ije/dyu148

7. Rothman KJ, Greenland S, Lash TL. Modern Epidemiology - Third Edition. Philadelphia: Wolters Kluwer Health Lippincott Williams \& Wilkins; 2008.

8. Lundberg I, Hemmingsson T, Hogstedt C. Work and social inequalities in health in Europe. Brussels: P.I.E. Peter Lang SA; 2007. 
9. Milner A, Spittal MJ, Pirkis J, Lamontagne AD. Suicide by occupation: systematic review and meta-analysis. Br J Psychiatry. 2013;203(6):409-16. https://doi.org/10.1192/bjp. bp. 113.128405

10. Lorant V, Deliege D, Eaton W, Robert A, Philippot P, Ansseau M. Socioeconomic inequalities in depression: a metaanalysis. Am J Epidemiol. 2003;157(2):98-112. https://doi. org/10.1093/aje/kwf182

11. Grittner U, Kuntsche S, Gmel G, Bloomfield K. Alcohol consumption and social inequality at the individual and country levels--results from an international study. Eur J Public Health. 2013;23(2):332-9. https://doi.org/10.1093/eurpub/ cks044

12. Niedhammer I, Bourgkard E, Chau N. Occupational and behavioural factors in the explanation of social inequalities in premature and total mortality: a 12.5-year follow-up in the Lorhandicap study. Eur J Epidemiol. 2011;26(1):1-12. https:// doi.org/10.1007/s10654-010-9506-9

13. Niedhammer I, Chastang JF, David S, Kelleher C. The contribution of occupational factors to social inequalities in health: findings from the national French SUMER survey. Soc Sci Med. 2008;67(11):1870-81. https://doi.org/10.1016/j. socscimed.2008.09.007

14. Chazelle E, Lemogne C, Morgan K, Kelleher CC, Chastang $\mathrm{JF}$, Niedhammer I. Explanations of educational differences in major depression and generalised anxiety disorder in the Irish population. J Affect Disord. 2011;134(1-3):304-14. https://doi. org/10.1016/j.jad.2011.05.049

15. Niedhammer I, Lesuffleur $\mathrm{T}$, Coutrot $\mathrm{T}$, Chastang JF. Contribution of working conditions to occupational inequalities in depressive symptoms: results from the national French SUMER survey. Int Arch Occup Environ Health. 2016;89(6):1025-37.https://doi.org/10.1007/s00420-016$1142-6$

16. Borenstein M, Hedges LV, Higgins JPT, Rothstein HR. Introduction to meta-analysis: John Wiley \& Sons, Ltd. ISBN: 978-0-470-05724-7; 2009. https://doi. org/10.1002/9780470743386
Isabelle Niedhammer, PhD, ${ }^{1,2}$ Allison Milner, $\mathrm{PhD},{ }^{3}$ Katrina Witt, DPhil, ${ }^{4}$ Justine Klingelschmidt, $\mathrm{MPH},{ }^{1,2,5}$ Imane Khireddine-Medouni, MPH, MD, ${ }^{5}$ Evangelos C Alexopoulos, MD, PhD, ${ }^{6}$ Susanna Toivanen, $\mathrm{PhD},{ }^{7}$ JeanFrançois Chastang, $\mathrm{PhD},{ }^{1,2}$ Anthony D LaMontagne, $\mathrm{ScD}^{8}$

1 INSERM, U1085, Research Institute for Environmental and Occupational Health (IRSET), Epidemiology in Occupational Health and Ergonomics (ESTER) Team, Angers, France.

2 University of Angers, Epidemiology in Occupational Health and Ergonomics (ESTER) Team, Angers, France.

${ }^{3}$ University of Melbourne, Melbourne School of Population and Global Health, Centre for Health Equity, Melbourne, Australia.

${ }^{4}$ Monash University, Turning Point, Eastern Health Clinical School, Fitzroy, Australia.

${ }^{5}$ Santé publique France, Direction Santé Travail, SaintMaurice, France.

6 Occupational Health Unit, "IASO" General Hospital, Athens, Greece.

${ }^{7}$ Stockholm University, Centre for Health Equity Studies, Stockholm, Sweden.

${ }^{8}$ Deakin University, Centre for Population Health Research, School of Health \& Social Development, Geelong, Australia. 